Gut, 1978, 19, 91-94

\title{
Treatment of HBsAg-positive chronic active hepatitis with human fibroblast interferon
}

\author{
J. G. C. KINGHAM, N. K. GANGULY, Z. D. SHAARI, R. MENDELSON, \\ M. J. McGUIRE, S. J. HOLGATE, T. CARTWRIGHT, G. M. SCOTT, \\ B. M. RICHARDS, AND R. WRIGHT
}

From the Professorial Medical Unit, Southampton General Hospital, and Searle Research Laboratories, High Wycombe, Bucks.

SUMMARY Two patients with HBsAg positive chronic active hepatitis have been treated with human fibroblast interferon $10^{7}$ units daily for two weeks. Before treatment, both patients had high levels of hepatitis B surface antigen, core antibody, and DNA-binding antibody in the blood and one patient had a fourfold rise in serum AST. During treatment there was a striking fall in the core antibody titre and also in the DNA-binding antibody, which has been maintained for several months subsequently; in one patient the initially high AST level fell to normal. No significant adverse effects occurred, and these observations should encourage further trials of fibroblast interferon in hepatitis $B$.

Chronic hepatitis B infection is a major clinical problem, but there is no established method of treatment for the liver disease or for the elimination of the carrier state.

Two recent reports have demonstrated modification of certain markers of chronic hepatitis B infection in man by the administration of human interferon. Greenberg et al. (1976) treated four HBsAg-positive chronic active hepatitis patients with human leucocyte interferon and Desmyter et al. (1976) used human fibroblast interferon to treat another patient. Among the changes in the markers of hepatitis B infection which they observed were a fall in the Dane particle core antigen and DNA polymerase activity, elimination of the $e$ antigen, and depression of the concentration of hepatitis B core antigen in the liver. One or more of these changes was observed if the interferon was given for a period of $\mathbf{1 0}$ days to two weeks, but was transient, and more prolonged treatment was necessary to modify the titre of HBsAg. Treatment of chimpanzees chronically infected with hepatitis B virus using fibroblast interferon (Desmyter et al., 1976) or an interferon inducer (Purcell et al., 1976) has produced similar results.

We here report the effect of administering human fibroblast interferon (HFIF) to two patients with HBsAg-positive chronic active hepatitis.

Received for publication 2 September 1977

\section{Methods}

Two patients with HBsAg-positive chronic active hepatitis were treated in hospital with HFIF $10^{7}$ units daily by subcutaneous or intramuscular injection for two weeks. The human fibroblast interferon was produced from a newly established line of human fetal lung fibroblast cells by induction with poly-I-C and superinduction with actinomycin $\mathrm{D}$ and cycloheximide (Sehgal et al., 1976). It was concentrated by ultrafiltration and purified by precipitation with ammonium sulphate and chromatography on conconavalin A sepharose, giving a final activity of $10^{6}$ units interferon $/ \mathrm{mg}$ protein and a concentration of $10^{7}$ units $/ \mathrm{ml}$. Circulating interferon levels were assayed serially during treatment by the $50 \%$ inhibition of cytopathic effect of Sindbis virus in Vero cells (Chisholm and Cartwright, 1975).

Serial specimens of blood were taken for assays of markers of hepatitis B infection, immunological studies, tests of liver function, including aspartate aminotransferase (AST), haemoglobin, white blood cell $(w b c)$ and platelet counts, and tests of renal function. The hepatitis $B$ markers measured on coded specimens of serum included HBsAg, HBsAb, anti-HBc, $e$ antigen and antibody, and the presence of Dane particles. HBsAg was measured by passive haemagglutination (Hepatest Wellcome Reagents Ltd.) and radioimmunoassay (Ausria II-Abbott 
Laboratories). HBsAb was measured by radioimmunoassay (Ausab.-Abbott Laboratories). Anti$\mathrm{HBc}$ titres were measured by complement fixation in doubling dilutions in microtitre plates. The $\mathrm{HBcAg}$ was extracted from post-mortem human liver from an immunosuppressed patient (kindly provided by $\mathrm{Mr}$ B. Cohen of the PHLS Laboratories, Colindale). The reaction was confirmed by counter-electrophoresis in both patients, and aggregates of HB core particles and antibody were observed in the excised precipitin line by electron microscopy with negative staining. $e$ antigen and antibody were detected by immunodiffusion in agar (Nielsen et al., 1974) using reference sera kindly provided by Dr Nielsen. Serum specimens were examined for Dane particles by electron microscopy with negative staining as described previously (Wright, 1970) using a Phillips 300 electron microscope. Double-stranded DNA-binding antibodies, which are known to be raised in acute and chronic hepatitis B (Jain et al., 1976) were measured by a modification of the Farr technique (Carr et al., 1969). Binding was assayed at $4^{\circ} \mathrm{C}$ using calf thymus DNA-labelled with tritiated actinomycin $D$; the normal range in our laboratory is $5-11 \%$.

\section{Results}

Patient 1, J. H., a 57 year old male, was found to have a finely nodular enlarged liver at laparotomy for a duodenal ulcer in January 1976. Liver biopsy showed typical features of chronic aggressive hepatitis with early cirrhosis. $\mathrm{HBsAg}$ in serum was positive, $\mathrm{HBsAb}$ negative, and $e$ antigen and antibody negative. Serum Dane particles were scanty. Liver function tests were normal, apart from a slight rise in the AST. The patient remained well, with persistently positive $\mathrm{HBsAg}$ and mildly raised AST from January to November 1976, when repeat liver biopsy was essentially unchanged.

Patient 2, D. P., a 22 year old drug addict, contracted mild hepatitis B in June 1975. Hepatosplenomegaly with raised AST persisted, and in December 1975 liver biopsy showed features of chronic aggressive hepatitis. $\mathrm{HBsAg}$ and $e$ antigen were positive. Repeat liver biopsy in October 1976 confirmed the diagnosis of chronic active hepatitis. HBsAg remained positive, but $e$ antigen had become negative.

On 8 December 1976, both patients were admitted for treatment with interferon, at which time both were asymptomatic but had hepatomegaly. Neither reacted to a test dose of 50000 U HFIF in $0.1 \mathrm{ml}$ tissue culture medium intradermally. Thereafter, patient 1 was given $10^{7}$ U HFIF in $1 \mathrm{ml}$ subcutaneously to alternate upper arms daily for 14 days, and plasma levels up to 10 units per $\mathrm{ml}$ interferon were achieved. The patient tolerated the injections well, with only slight local tenderness and erythema after 24 hours, which decreased during the course of treatment.

In patient 2, a 3-cm indurated area developed at the site of the first injection of $10^{7}$ units of HFIF subcutaneously, but subsequent intramuscular injections of the same dose into the buttocks daily for 14 days produced no local reaction, and circulating interferon levels up to 100 units per $\mathrm{ml}$ were achieved. Neither patient had pyrexia or tachycardia, and haemoglobin, white blood cells and platelet counts were normal throughout.

In patient 1 , the liver function tests remained normal, but in patient 2 the AST rose from 140 units before treatment to 183 units on day 6 , and subsequently fell below pre-treatment levels (Figure). In both patients there was a marked fall in anti-HBc during treatment, and the titre has remained low for four months following treatment (Figure). HBsAg titres fluctuated transiently during treatment, $e$ antigen and antibody and HBsAb have remained persistently negative, and in both patients only occasional Dane particles have been observed in the serum throughout. In both patients DNA-binding antibodies were raised before treatment to the range expected in chronic active hepatitis, but fell to normal during treatment, where they have since remained (Figure).

\section{Discussion}

Both patients with HBsAg-positive chronic active hepatitis reported here showed a marked fall in the titre of antibody to hepatitis core antigen during a two-week course of treatment with human fibroblast interferon. This confirms earlier reports of the modification of hepatitis B markers by interferon in both man (Desmyter et al., 1976; Greenberg et al., 1976) and the chimpanzee (Desmyter et al., 1976; Purcell et al., 1976). Greenberg et al. (1976) showed depression of DNA polymerase activity, a decrease in Dane particle-associated DNA, and dissappearance of the $e$ antigen after treatment with interferon. They also observed a fall in the titre of $\mathrm{HBcAg}$. Prolonged treatment was necessary to alter the HBsAg titre significantly. We did not measure DNA polymerase activity, but since this correlates well with the presence of the $e$ antigen, which was negative in our patients, and Dane particles in the serum (Nordenfelt and Kjellen, 1975), which were sparse, it is likely that the DNA polymerase titre was low or absent.

The marked fall in anti-HBc, as well as DNAbinding antibodies, in our patients following 


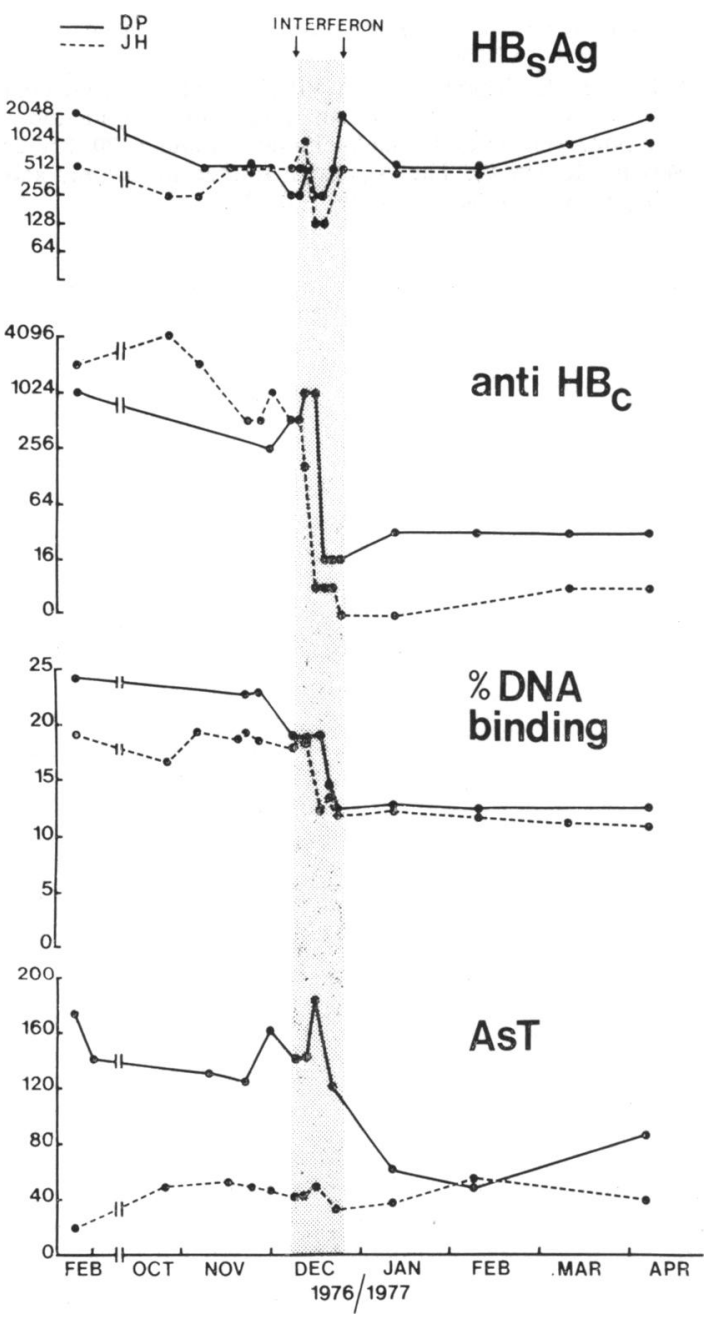

Figure The effect of treatment with human fibroblast interferon $10^{7}$ units daily on titres of $H B s A G$, anticore antibody and DNA-binding antibody, and on AST levels in two patients with chronic active hepatitis.

interferon treatment is intriguing. Interferon may release hepatitis $B$ core antigen from the liver, which becomes complexed with anti-HBc, producing a fall in titre. The observations of Desmyter et al. (1976) on the decrease in core antigen in the liver after treatment with interferon favours this possibility, as does the fall in titre of HB core antigen in serum reported by Greenberg et al. (1976).

The fall in DNA-binding antibody in the serum may have a similar explanation. Free circulating Dane particle-associated DNA has been demonstrated in the serum in hepatitis B infection (Hung et al., 1975). Interferon treatment, by releasing specific Dane particle-associated DNA or hepatocyte nuclear DNA, may react with antibody which we are detecting using calf thymus DNA to produce the fall in binding antibody observed in both patients. Alternatively, interferon, by stopping viral replication in the liver, may reduce the production of core antigen and its associated DNA, causing a fall in the titre of anti-HBc and DNA-binding antibodies. This is favoured by the persistence of low titres for some months after treatment and the fall in AST level in one patient.

The titres of HBsAg did not fall significantly during treatment, which is not surprising as the studies of Greenberg et al. (1976) suggest that a more prolonged course of treatment is necessary before any effect is observed.

We suggest that these results should encourage further trials of interferon in hepatitis B, using more prolonged courses of treatment, and that human fibroblast interferon appears to be well tolerated in the dosage used. In particular, the haematological depression which may occur with leucocyte interferon (Greenberg et al., 1976) was not observed.

We wish to thank Dr A. J. Hale and Dr G. R. Venning for support and encouragement, $\mathrm{Dr} R$. Dathan and $\mathrm{Mr} \mathrm{J}$. Webster for referring patients for treatment, and Mrs G. Le Du for laboratory assistance. N. K. G. is in receipt of a Commonwealth Medical Fellowship.

\section{References}

Carr, R. I., Koffler, D., Agnello, V., and Kunkel, H. G. (1969). Studies on DNA antibodies using DNA labelled with actinomycin D $\left({ }^{3} \mathrm{H}\right)$ or dimethyl $\left({ }^{3} \mathrm{H}\right)$ sulphate. Clinical and Experimental Immunology, 4, 527-536.

Chisholm, M., and Cartwright, T. (1975). Interferon production in Hodgkin's disease. Clinical and Experimental Immunology, 20, 419-425.

Desmyter, J., Ray, M. B., De Groote, J., Bradburne, A. F., Desmet, V. J., Edy, V. G., Bissiau, A., De Somer, P., and Mortelmans, J. (1976). Administration of human fibroblast interferon in chronic hepatitis B infection. Lancet, 2, 645-647.

Greenberg, H. B., Pollard, R. B., Lutwick, L. I., Gregory, P. B., Robinson, W. S., and Merigan, T. C. (1976). Effect of human leucocyte interferon on hepatitis B virus infection in patients with chronic active hepatitis. New England Journal of Medicine, 295, 517-522.

Hung, P. P., Mao, J. C.-H., Ling, C. M., and Overby, L. R. (1975). Hybridisation of Dane particle DNA with the free plasma DNA of hepatitis carriers. Nature, 253, 571-572.

Jain, S., Markham, R., Thomas, H. C., and Sherlock, S. (1976). Double-stranded DNA-binding capacity of serum in acute and chronic liver disease. Clinical and Experimental Immunology, 26, 35-41.

Nielsen, J. O., Dietrichson, O., and Juhl, E. (1974). Incidence and meaning of the $e$ determinant among hepatitis B 
antigen-positive patients with acute and chronic liver disease. Lancet, 2, 913-915.

Nordenfelt, E., and Kjellen, L. (1975). Dane particles, DNA polymerase and $e$ antigen in two different categories of hepatitis B antigen carriers. Intervirology, 5, 225-232.

Purcell, R. H., Gerin, J. L., London, W. T., Wagner, J., McAuliffe, V. J., Popper, H., Palmer, A. E., Lvovsky, E., Kaplan, P. M., Wong, D. C., and Levy, H. B. (1976).
Modification of chronic hepatitis $\mathbf{B}$ virus infection in chimpanzees by administration of an interferon inducer. Lancet, 1, 757-759.

Sehgal, P. B., Tamm, I., and Vilcek, J. (1976). Mechanism of enhancement of human interferon production by actinomycin D and cycloheximide. Virology, 70, 256-259.

Wright, R. (1970). The Australia antigen in chronic active hepatitis. Vox Sanguinis, 19, 320-326. 